\title{
THE CONTROL OF THE DOSAGE OF ANTISERUM IN THE TREAT- MENT OF PNEUMOCOCCAL PNEUMONIA. I. A STUDY OF THE MECHANISM OF THE SKIN REACTION TO TYPE SPECIFIC POLYSACCHARIDE
}

\author{
BY W. BARRY WOOD, JR. \\ (From the Biological Division of the Department of Medicine, Johns Hopkins Hospital and \\ University, Baltimore)
}

(Received for publication August 23, 1939)

In 1917 Dochez and Avery (1) isolated from cultures of actively growing pneumococci and from the blood and urine of patients suffering from pneumonia a soluble substance which possessed the property of precipitating homologous antibody. Finding that this "specific soluble substance" neutralized the protective action of antipneumococcal immune bodies, Cole (2), in the same year, advanced an important hypothesis. He suggested that antiserum administered therapeutically could not be expected to influence the course of pneumococcal pneumonia until an excess of antibody had been given over and above that needed to neutralize the specific soluble substance circulating in the patient's blood. The specific soluble substance is now known to be a complex polysaccharide derived from the capsule, specifically antigenic, and chemically unique for each type of pneumococcus. More recently it has been found in high concentration in pneumonic pulmonary exudates (3) and has been shown to nullify the opsonizing properties of homologous antibody in vitro (4), as well as neutralize its protective action in vivo.

The importance of the hypothesis advanced by Cole lies in the fact that the quantity of polysaccharide to be neutralized in the blood of patients with pneumonia varies within extremely wide limits. The production of polysaccharide depends upon many factors, including the duration and extent of the infection, the rapidity with which the pneumococci are multiplying in the lung, invasion of the blood stream, and the polysaccharideproducing power of the particular type of pneumococcus causing the pneumonia. ${ }^{1}$ These com-

\footnotetext{
1 It has been shown by Ward (5) that the polysaccharide-producing power of different types of pneumococci varies appreciably. Type III pneumococcus, for example, produces considerably more polysaccharide than type I.
}

plex variables make it impossible to predict the "neutralizing dose" of antibody for any individual patient. Unfortunately, the logical concept of the interaction of antibody and polysaccharide has been almost entirely ignored by clinicians, as evidenced by the fact that only rarely is any attempt made to control the dosage of antibody in the serum treatment of pneumonia. It is still a common practice to give antiserum according to arbitrary rules based upon specified clinical criteria (6). As will be illustrated by cases encountered during the course of the present study (7), variations in antibody requirements are too great to be defined even approximately by any such rules.

The failure of clinicians to adopt methods of controlling the dosage of antiserum may best be explained by the fact that the usual serological tests designed to detect the presence of antibody in the blood are not practical. Agglutination methods entail the use of specific antigens, usually fresh cultures or vaccines, for each type of pneumococcus and require a sample of the patient's blood serum for every determination. Precipitin tests are open to similar criticisms, and at times the significance of a positive reaction with either method is extremely difficult to evaluate, since agglutinins and precipitins may occasionally be detected in the blood before sufficient antiserum has been administered $(6,7,8)$.

In 1933 Francis (8) recommended as a guide to serum therapy a skin test with the specific capsular polysaccharide of the pneumococcus. Two years earlier Tillet and Francis (9) had shown that pneumococcal polysaccharides when injected intradermally into patients convalescent from pneumonia caused an immediate "wheal and erythema" skin reaction appearing in 10 to 20 minutes and fading after 1 to 2 hours. The polysaccharide causing the reaction was found to 
be always homologous in type to the pneumococcus causing the pneumonia. The patient's capacity to react became manifest coincident with recovery from the infection and was invariably associated with the presence of type-specific antibodies (agglutinins and precipitins) in the blood. Francis and Tillet in 1931 (10) extended their observations and reported that recovery from type I pneumonia in serum-treated cases was associated with the development of a positive skin reaction to type I polysaccharide. In fatal cases, however, treated with type I antiserum, although typespecific antibodies were sometimes present in the blood, the skin test remained negative. In every case where the skin test became positive the patient recovered.

These early observations suggested that the skin test with capsular polysaccharide might serve to indicate when serum therapy could safely be discontinued. After employing the test in fortyeight cases of serum-treated type I pneumonia, Francis (8) concluded that the skin test was a valuable guide to serum therapy and a definite prognostic aid. He pointed out that the test was far simpler and more practical than agglutination tests and that it possessed the additional advantage of serving as more than a mere index of circulating antibodies, a positive reaction being apparently the resultant of the presence of specific antibody in the blood and a state of reactivity of the skin associated with recovery. "When positive," he wrote, "it invariably denotes that recovery has begun; when negative it indicates further serum therapy."

Although the important observations of Francis were published in 1933, the skin test with capsular polysaccharide has been used very little as a guide to serum treatment. Abernethy (11) and MacLeod, Hoagland and Beeson (12) at the Hospital of the Rockefeller Institute have extended and confirmed the studies of Francis, and the test has been used routinely in that hospital for several years. Elsewhere, however, it has found little favor. The apparent disrepute into which the test has fallen at the hands of other writers (6, $13,14,15$ ) would seem to be explained by the fact that the mechanism of the Francis skin reaction is not clearly understood, and its several limitations have not been carefully enough defined to prevent misinterpretation.
The purpose of the present investigation has been to determine the various factors which control the skin reaction to type-specific pneumococcal polysaccharide and, by a detailed clinical study, to evaluate further its advantages and disadvantages as a practical guide to serum therapy. The results of the clinical study will be reported in a second publication (7).

\section{METHODS}

Specific capsular polysaccharides. The type-specific capsular polysaccharides of pneumococci of types I-VIII and XIV were kindly furnished by Dr. L. D. Felton of the National Institute of Health. They were prepared according to the methods of Felton (16), and none of the final products gave positive reactions for protein or contained " C" fraction of the pneumococcus when tested against heterologous serum. ${ }^{2}$ The polysaccharides were dissolved in normal salt solution at a dilution of $1: 10,000$ and were stored in the ice box.

Skin tests with polysaccharide. Skin tests were performed by injecting $0.1 \mathrm{cc}$. of a solution of polysaccharide into the skin of the volar surface of the forearm or upper arm. (In a few cases the pectoral area and epigastrium were also used.) As a control, $0.1 \mathrm{cc}$. of normal salt solution was always injected a few centimeters from the site of injection of the polysaccharide. All injections were intradermal and the tests were read after 15 to 30 minutes. A test was considered positive only when there appeared a definite wheal surrounded by an area of erythema.

Antipneumococcal serum. Antipneumococcal serum was supplied by the Lederle Laboratories, Inc. and E. R. Squibb and Sons. Serum generously donated for "clinical trial" was used almost exclusively and included both horse and rabbit serum. The antibody titers of the sera varied from 1,000 to 10,000 units per cc. After a small initial dose, serum was injected intravenously at hourly intervals in doses varying from 10,000 to 100,000 units of antibody. A skin test was performed before each injection of serum. As soon as a positive skin reaction was obtained, regardless of the clinical status of the patient, all serum therapy was discontinued and under no circumstances was it resumed unless the skin test became negative.

Skin tests with polysaccharide and serum. A limited number of skin tests were performed in which both type I polysaccharide and various dilutions of type I antipneumococcal rabbit serum were injected into the same site. The details of these tests are described below. They were performed only on normal individuals who failed to react to the intradermal injection of type I polysaccharide alone.

2 MacLeod, Hoagland, and Beeson have emphasized the importance of using preparations which contain no "C" fraction of the pneumococcus, if false positive reactions are to be avoided. 
Passive transfer tests. Passive transfer tests were done with the blood serum of patients suffering from type I pneumonia, the blood being drawn both at the time of admission to the hospital and after the polysaccharide skin test had become positive under treatment with antiserum. The donor's serum was injected intradermally into normal recipients who did not react to type I polysaccharide alone. The injection of donor's serum often caused a local erythematous reaction which faded in a few hours. The local reaction was allowed to subside before $0.1 \mathrm{cc}$. of type I polysaccharide was injected into the same site. As a control, a similar test was done with a heterologous polysaccharide (type II or type III). All reactions were read as described above for the routine skin test with polysaccharide.

Mouse protection tests. Protective antibodies in the serum of patients under treatment were measured by mouse protection tests. A pure-bred strain of mice (C.F.1) was used in all experiments. The mice were injected intraperitoneally with $0.5 \mathrm{cc}$. of various dilutions of a 14-hour blood-broth culture of type I pneumococci immediately after having received by the same route 0.5 cc. of a 1 to 5 dilution of the serum to be tested. The dilutions of culture varied logarithmically from $1: 5$ to $1: 50,000,000$. Five mice were injected with each dilution of culture. The type I pneumococcus used was supplied by Dr. Felton and after several passages through mice was highly virulent, $10^{-8} \mathrm{cc}$. of a 14-hour culture killing mice regularly in 20 hours. The virulence of the culture was tested in every experiment. Each test was terminated at the end of 96 hours and all mice living at the end of this time were counted as survivals. The final results were expressed in units ${ }^{3}$ of antibody per cc. of patient's blood.

Agglutinin tests. Tests for agglutinins were done by the Sabin microscopic method (17).

\section{RESULTS}

\section{The nature of the skin reaction to polysaccharide}

During the early studies of the Francis skin test it was found that positive reactions to a given type of polysaccharide occurred only when agglutinins and precipitins were present in the blood $(8,9,10)$. It is well known that pneumococcal polysaccharide reacts in vitro with antibody of the same type to form a precipitate (precipitin reaction). These two facts suggest that the Francis skin reaction may be the result of a local union of polysaccharide and antibody in the skin at the site of injection of the polysaccharide. To test this hypothesis, an attempt was made to produce in normal individuals an immediate wheal

\footnotetext{
${ }^{8}$ One unit of antibody protects a mouse against 1,000,000 lethal doses of pneumococci.
}

and erythema skin reaction by injecting antibody and polysaccharide into the same site. This was done in the following experiment.

Five normal subjects were selected who failed to react to the intracutaneous injection of types $I$, II and III polysaccharides. ${ }^{4}$ Type I antipneumococcal rabbit serum containing 10,000 units of antibody per cc. was diluted with normal salt solution to concentrations of $1: 10,1: 100,1: 1,000$ and $1: 10,000$. One-tenth cc. of each dilution of antiserum was injected into the volar surface of the forearm and 30 minutes later $0.1 \mathrm{cc}$. of the solution of type I polysaccharide was injected into the same sites. On the opposite arm a control experiment was carried out simultaneously with the same dilutions of type I antiserum and a heterologous polysaccharide (type II or type III). All five subjects reacted in exactly the same manner as summarized in the following table :

TABLE I

Reactions to intradermal injections of type I antipneumococcal rabbit serum and capsular polysaccharides

\begin{tabular}{c|c|c|c|c}
\hline \hline Dilution of serum & $1: 10$ & $1: 100$ & $1: 1000$ & $1: 10.000$ \\
\hline Type I polysaccharide...... & $+^{*}$ & + & + & - \\
\hline $\begin{array}{r}\text { Type II or type III polysac- } \\
\text { charide................. }\end{array}$ & $-{ }^{*}$ & - & - & - \\
\hline
\end{tabular}

* The intradermal injection of a $1: 10$ dilution of rabbit serum of ten causes a mild local erythematous reaction, but this does not interfere with the reading of the polysaccharide skin reaction if a suitable control is available for comparison.

The positive reactions observed in these tests simulated exactly the characteristic immediate wheal and erythema reaction of the Francis skin test. It should be emphasized that the reactions were produced in normal individuals who had not recently had pneumonia and who did not react to intradermal injections of the type I polysaccharide alone. A positive reaction resulted only when the antibody and polysaccharide injected were of the same type and only when the antibody was introduced in sufficient concentration. (Approximately 1 unit or more in the 0.1 cc. injected.) The dilution of polysaccharide injected was not varied.

4 As shown by Alston and Lowdon (18) a considerable number of normal individuals may react to pneumococcal polysaccharides. 
To test further the hypothesis that the Francis skin reaction results from a local union of antibody and polysaccharide in the skin, an attempt was made to transfer passively a positive reaction. The usual passive transfer technique was used as outlined above. Blood serum of four patients with type I pneumonia was obtained before and after treatment with specific antiserum. The serum drawn before treatment in each case contained no type I agglutinins, whereas that taken after treatment (when the Francis skin test had become positive) strongly agglutinated type I pneumococci. One-tenth cc. of the donor serum, taken before and after treatment, was injected intracutaneously into recipients who were nonreactors to type I polysaccharide. After the local erythematous reactions caused by the serum injections had subsided, $0.1 \mathrm{cc}$. of the solution of type I polysaccharide was injected into the same sites. With the same donor's sera a similar series of injections was performed with type III polysaccharide as a control. The results of the passive transfer tests may be summarized as follows:

TABLE II

Immediate skin reactions in passive transfer tests with human serum and capsular polysaccharides

\begin{tabular}{c|c|c}
\hline \hline Donor's blood serum & $\begin{array}{c}\text { Before treatment } \\
\text { with type I anti- } \\
\text { serum (type I } \\
\text { agglutinins } \\
\text { absent) }\end{array}$ & $\begin{array}{c}\text { After treatment } \\
\text { with type I anti- } \\
\text { serum (type I } \\
\text { agglutinins } \\
\text { present) }\end{array}$ \\
\hline $\begin{array}{c}\text { Type I polysaccharide (ho- } \\
\text { mologous type)......... }\end{array}$ & - & + \\
\hline $\begin{array}{c}\text { Type III polysaccharide } \\
\text { (heterologous type) ...... }\end{array}$ & - & - \\
\hline
\end{tabular}

In every case where the donor's serum contained type I agglutinins, a positive reaction was produced by the injection of type I polysaccharide. When the donor serum contained no type I agglutinins, no reaction was observed. None of the serum-polysaccharide tests done with the heterologous (type III) polysaccharide was positive. The positive reactions produced by this passive transfer technique were indistinguishable from those seen in the usual skin reaction to polysaccharide.

In both of the above experiments, it was possible to produce the characteristic immediate wheal and erythema skin reaction to type I capsular polysaccharide by merely "sensitizing" the skin locally by the intradermal injection of homologous antibody. As long as the antibody was present in sufficiently high titer, it seemed to make no difference whether its source was antipneumococcal rabbit serum or the blood serum of patients convalescing from pneumonia after adequate treatment with therapeutic antiserum. The results of both experiments strongly support the view that the Francis skin reaction is due to a local union of antigen and antibody at the site of injection of the polysaccharide.

\section{The relationship of the titer of circulating antibody to the dermal reaction to capsular polysaccharide}

It has been shown by the experiments just described that, in order to produce an immediate wheal and erythema skin reaction by injecting antibody and homologous polysaccharide intradermally at the same site, it is necessary to inject a relatively large amount of antibody. This fact suggests that the titer of antibody in the blood serum of patients with pneumonia may be a determining factor in the production of a positive skin reaction. That specific antibodies may be present in the blood serum at a time when the polysaccharide skin test is negative has been well established $(8,9,10,13)$ but the relation of the titer of antibody to positive skin reactions has never been carefully studied.

In the following experiment the titer of antibody in the blood serum of three patients with type I pneumonia was followed throughout the course of serum therapy by means of mouse protection tests. Blood was drawn before and after each of the hourly injections of therapeutic serum (excluding the first 50,000 units) and at convenient intervals after serum therapy had been discontinued. The results of the antibody studies in two of the cases are depicted graphically in Figures 1 and 2. In all three cases protective antibodies appeared in the blood after the first 50,000 units of therapeutic serum had been given, although the Francis skin test remained negative. Not until the antibody titer had reached a level of one-tenth of a unit or more per cc. did the skin reaction become positive. These data indicate that not only the presence but the titer of type-specific antibodies in the blood serum is an important factor determining the reaction to in- 
Case 1.

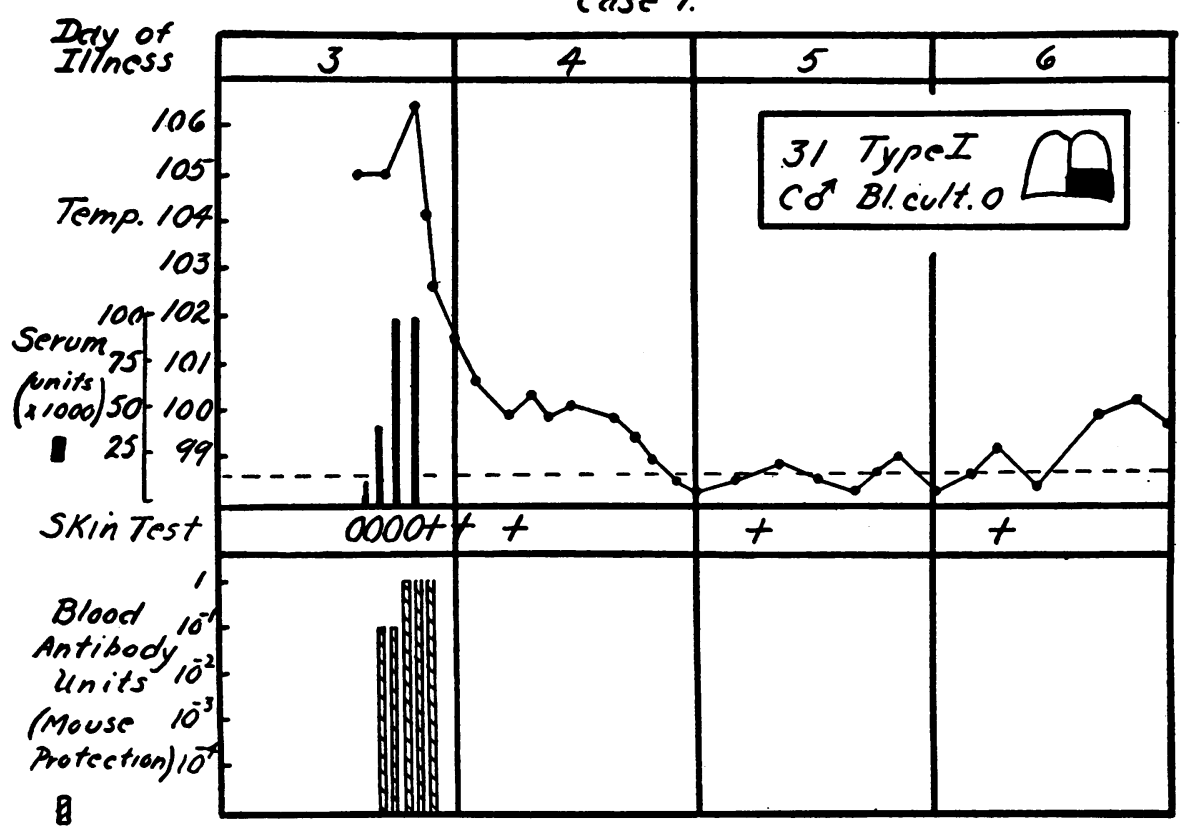

Fig. 1. Antibody Content of the Blood in Pneumococcal Pneumonia Treated With Antiserum

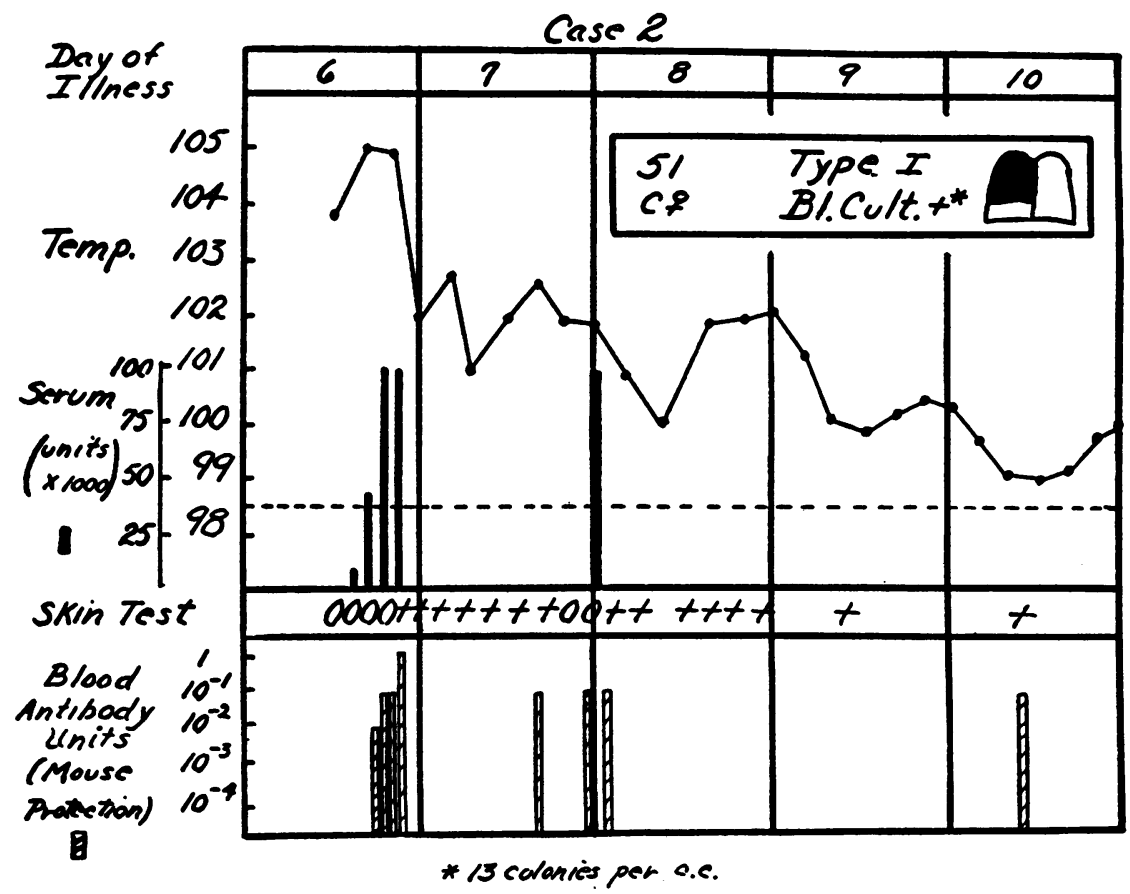

Fig. 2. Antibody Content of the Blood in Pneumococcal Pneumonia treated With ANtiserum 
tradermal injection of homologous capsular polysaccharide.

It will be noticed that in the case summarized in Figure 2 the skin reaction became negative on the second day without any demonstrable decrease in the titer of antibody in the blood at the time that the skin failed to react. This can be explained in one of two ways: Either the mouse protection method as used in these tests was too crude a measure of antibody to detect so slight a decrease as may have occurred; or else, the reactivity of the skin was temporarily depressed so that the amount of antibody in the blood was insufficient to cause the skin to react. As regards the first possibility no further data are available, but the following observations substantiate the view expressed by Francis that the reactivity of the skin to capsular polysaccharide may vary during the course of a pneumococcal pneumonia.

\section{The reactivity of the skin as a limiting factor in the skin reaction to capsular polysaccharide}

In their earliest investigations of the skin reaction to type-specific polysaccharide, Tillet and Francis observed that in fatal cases of pneumonia the skin reaction remained negative in spite of the presence of relatively large amounts of antibody in the blood. Francis noted that a positive reaction does not depend solely upon a high concentration of circulating antibodies, since in certain cases the titer of agglutinins was found to be the same before recovery, when the skin test was negative, as it was later, when the skin reaction had become positive. He concluded that a positive skin reaction to a given polysaccharide depended upon two factors: (1) the presence of homologous type-specific antibodies in the blood serum and (2) the state of reactivity of the skin. Postulating that an increase in the reactivity of the skin was associated with recovery from pneumonia, he suggested that the negative skin reactions encountered in fatal cases were due to a loss of cutaneous sensitivity.

As evidence that an increase in the reactivity of the skin was associated with recovery, Francis cited the experiments of Finland and Sutliff (13). They reported that skin tests done with both type I and type II polysaccharides became positive at the same time (approximately the time of crisis) in patients with type I pneumonia treated with bivalent antiserum (types I and II). There is good reason to believe that the blood of a patient suffering from type I pneumonia will acquire an excess of type II antibody before type I, if the patient is treated with bivalent antiserum containing approximately equal amounts of both antibodies $(2,19)$. This fact cannot be reconciled with the results of Finland and Sutliff's experiments unless it is assumed that the skin reaction to capsular polysaccharide depends upon an increase in reactivity of the skin occurring at the time of recovery rather than upon the appearance of an excess of homologous antibody in the blood.

Since skin tests were done at relatively infrequent intervals by Finland and Sutliff, their study of patients treated with bivalent serum was repeated. Two patients with type VII pneumonia, both critically ill with bacteremia, were treated with bivalent horse serum (types V and VII). In both cases the skin test with type $\mathrm{V}$ polysaccharide became positive after approximately 50,000 units of type $\mathrm{V}$ antibody had been administered, whereas a positive reaction with type VII polysaccharide was not obtained until 1,160,000 units of type VII antibody had been given in one case (see Figure 3) and 1,800,000 units in the other. In a case of type IV pneumonia treated with types IV and VIII serum the skin reaction to type VIII polysaccharide became positive after the injection of 15,000 units of type VIII antibody, in contrast to the type IV skin test which remained negative until 495,000 units of type IV antibody had been administered. In each case much more antibody was needed to produce a reaction to the polysaccharide which corresponded in type to the pneumococcus causing the pneumonia. The fact that the skin reaction to the polysaccharide of unrelated type became positive in each case long before the patient had received sufficient antibody to bring about recovery indicates clearly that the Francis skin reaction does not depend solely upon an increase in cutaneous reactivity occurring at the time of recovery.

That the reactivity of the skin to polysaccharide may actually change during the course of a pneumococcal pneumonia has never been clearly established. However, the following immunological studies carried out in an unusual case of 


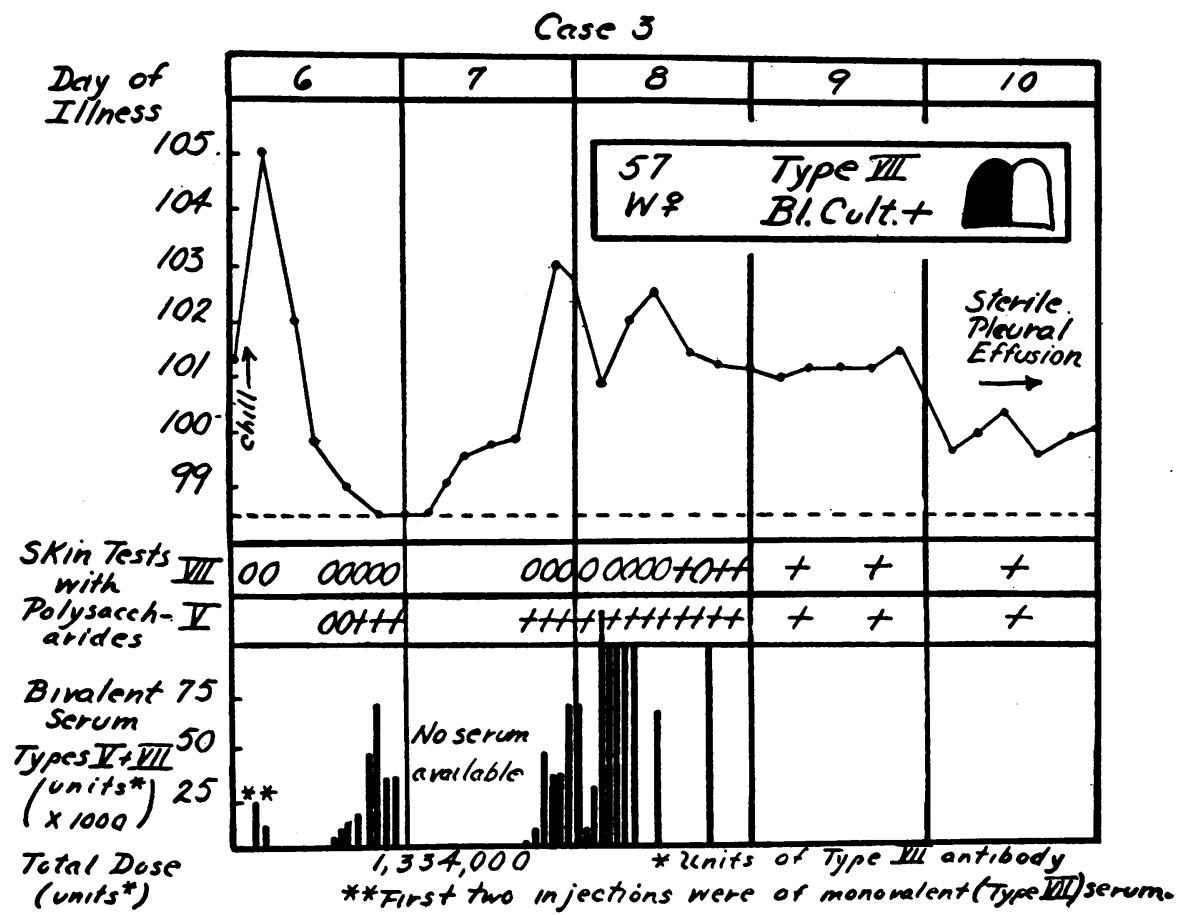

Fig. 3. Skin Reactions to Polysaccharides in Pneumonia Treated with Bivalent Antiserum

pneumonia would seem to prove conclusively that the skin may lose its power to react to injections of polysaccharide during the course of a severe pneumonia, even though a large excess of homologous antibody is present in the blood.

\section{PROTOCOL}

A 50-year-old colored woman was admitted to the hospital on the third day of an attack of lobar pneumonia which involved the left lower lobe. The sputum contained many type III pneumococci typed by direct quellung reaction and after mouse inoculation. No other type of pneumococcus was recovered from the sputum; the blood culture was negative. The patient was treated with type III antipneumococcal rabbit serum, and after she had received 160,000 units, the skin test with type III polysaccharide became positive and the temperature promptly fell to normal. (See Figure 4.) The noticeable improvement in the patient's condition which occurred at this time made it apparent that she had had a crisis. However, 12 hours later she experienced a shaking chill, the temperature rose to $104^{\circ}$, and the skin test became negative. It was thought that she had suffered a spread of the type III pneumonia and serum therapy was resumed. The skin reaction became positive after each of the first two injections of 80,000 units of serum only to become negative within a few hours. From then on it remained negative, in spite of continued intensive treatment with type III serum and in spite of the fact that agglutinin tests revealed a high titer of type III antibody circulating in the blood. Becoming rapidly worse the patient finally lapsed into coma 12 hours after the chill. Physical examination revealed signs of consolidation of the left upper as well as the left lower lobe (confirmed by $x$-ray). A blood culture, taken at the time of the chill, was reported positive 12 hours later, and, not type III, but type XVI pneumococci were isolated from the blood broth. The sputum was immediately retyped and was found to contain only type XVI pneumococci. It then became apparent that the patient had developed type XVI pneumonia involving the left upper lobe only 12 hours after recovering from a type III infection of her left lower lobe. Desperately ill, with a heavy bacteremia ( 22 colonies of type XVI pneumococcus per cc.), the patient was treated with large doses of sodium sulfapyridine intravenously (20). She responded dramatically to this treatment, regaining consciousness in less than 8 hours. Early the following morning, 16 hours after the first injection of sodium sulfapyridine, the temperature fell to normal, and thereafter the patient made an uneventful recovery. Meanwhile, during the course of the sulfapyridine therapy, the skin test with type III polysaccharide was performed repeatedly. While the patient was critically ill from the type XVI infection, the skin test remained persistently negative. Only after she had regained consciousness and the temperature had fallen to $99^{\circ}$, did the skin test with type III polysaccharide again become positive, to remain so throughout her convalescence. 


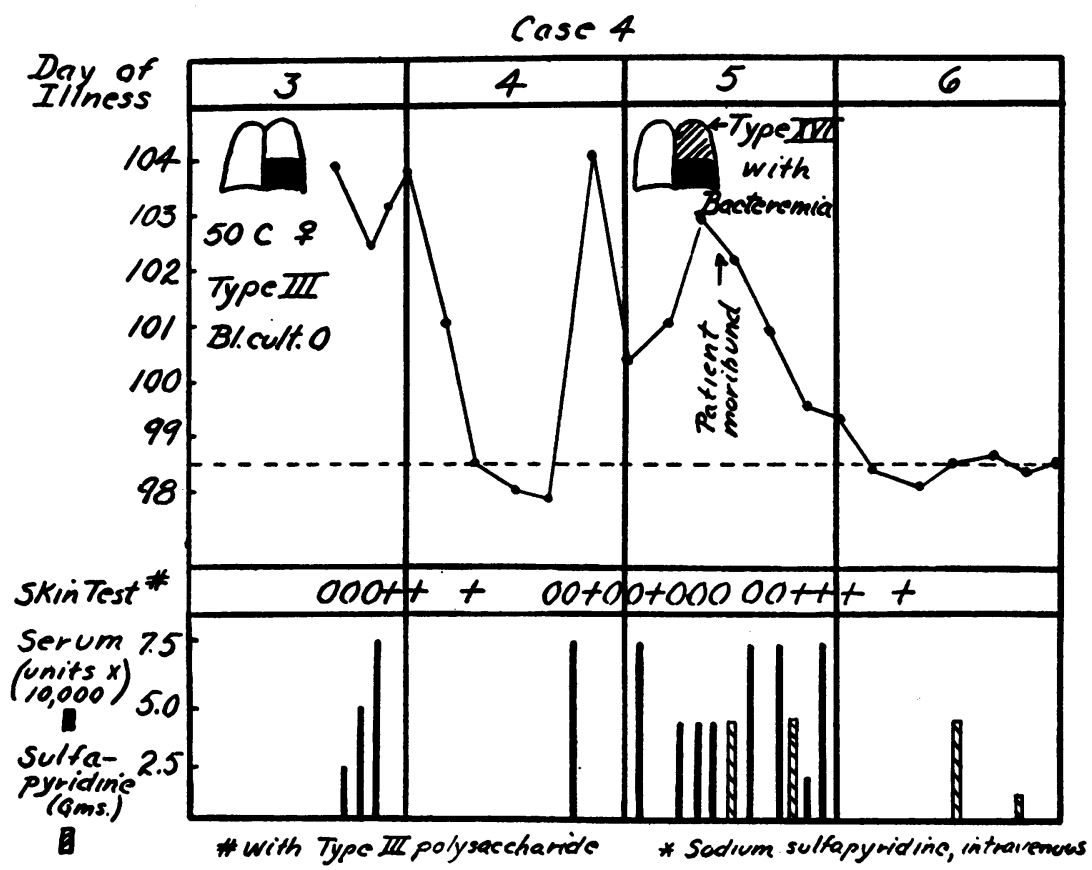

Fig. 4. Change of Reactivity of Skin to Polysaccharide in Pneumonia during Relapse Caused by Pneumococcus of a Different Type

The changes in the skin reaction to type III polysaccharide observed in this case during the course of the type XVI pneumonia cannot be attributed to a decrease in the titer of type III antibody in the blood. Careful examination of both blood and sputum revealed only type XVI pneumococci during the relapse so that there was no bacteriological evidence of a flare-up of the type III infection. Also, intensive therapy with type III antiserum was continued, and it is only reasonable to suppose that the serum treatment, in the absence of an active type III infection, caused a considerable excess of type III antibody to accumulate in the blood. That a high titer of type III agglutinins was present in the blood when the skin test remained negative was shown by agglutination tests. It is apparent that the failure of the skin to react to type III polysaccharide was due to a loss of cutaneous reactivity in some way associated with the "toxemia" of the type XVI pneumonia rather than to a decrease in the titer of type III antibodies in the blood. The loss of cutaneous reactivity was evidently progressive, as shown by the fact that the first two injections of serum after the chill caused the skin test to revert temporarily to positive, whereas re- peated injections thereafter failed to produce a positive reaction until finally the type XVI infection had been controlled.

It may be concluded from the observations made upon this patient and upon the patients treated with bivalent antiserum that, although the Francis reaction does not depend solely upon an increase in dermal reactivity occurring at the time of recovery, the skin of patients suffering from pneumonia may lose its power to react to injections of polysaccharide, even in the presence of large amounts of antibody in the blood. This loss of cutaneous reactivity is commonly associated with profound toxemia and, as emphasized by Francis, it usually indicates a poor prognosis.

\section{DISCUSSION}

Evidence has been presented that the immediate wheal and erythema skin reaction to capsular polysaccharides of the pneumococcus is due to the local union of antibody and polysaccharide in the skin. A positive skin reaction to the intradermal injection of a given type of polysaccharide has been shown by Francis and others to be invariably associated with the presence of 
homologous type-specific antibodies in the blood. Cutaneous reactions simulating exactly those seen in the Francis skin test have been produced by injecting homologous antiserum and polysaccharide into the same site of the skin of normal individuals who did not react to injections of the polysaccharide alone. The intracutaneous injection of antiserum "sensitized" the skin locally to the homologous polysaccharide, and the resulting skin reaction was indistinguishable from that caused by similar injections of polysaccharide alone in patients convalescing from pneumococcal pneumonia. Positive reactions were also passively transferred to negative reactors by the usual passive transfer technique. The factor, passively transferred, which caused the positive reaction, was shown to be the type-specific antibody, since the skin was sensitized only when the donor's serum contained antibody and reacted only to polysaccharide of the homologous type.

The Francis skin reaction may perhaps be best regarded as the result of a precipitin reaction occurring locally in the skin. It is conceivable that antibody circulating in the blood stream combines with the locally injected homologous polysaccharide, and sets up a characteristic dermal reaction. In order that such a dermal reaction be produced, two conditions must obtain.

First, there must be sufficient antibody in the blood to react with the $.01 \mathrm{mgm}$. of polysaccharide injected intradermally, and the polysaccharideantibody reaction must be sufficiently strong to cause the skin to react locally. That enough antibody must be present was shown by the fact that, in order to produce a positive reaction by injecting $0.1 \mathrm{cc}$. each of antiserum and polysaccharide intradermally at the same site, it was necessary to introduce more than one-tenth of a unit of antibody. Likewise, patients treated with antiserum did not develop a positive reaction as soon as antibody could be demonstrated in the blood but only after a relatively high titer of antibody had been reached.

Secondly, the dermal reaction must depend in part upon the state of reactivity of the skin. That cutaneous reactivity may be depressed during the course of pneumonia has been shown in the case of type III pneumonia reported above. A similar decrease in the reactivity of the skin to tuberculin and Dick and Schick toxins is known to occur during the febrile stage of pneumonia and other acute infectious diseases (21). The most logical explanation for the negative skin reactions to polysaccharide observed repeatedly in patients dying from pneumonia, in spite of the presence of large amounts of antibody in the blood, would seem to be a loss of cutaneous reactivity.

As a test for the presence of pneumococcal antibody in the blood serum the Francis skin test is extremely crude. Finland and Sutliff (22) have found it less sensitive than either mouseprotection or agglutinin tests. Not only is it relatively insensitive but also the end point at which the reaction occurs is variable depending upon the state of reactivity of the skin. Strangely enough, it seems to be these two properties which render the skin test with pneumococcal polysaccharide a more reliable guide of prognosis and serum therapy than any of the usual serological tests for antibody (7).

\section{SUMMARY}

1. The immediate wheal and erythema skin reaction to pneumococcal capsular polysaccharides which has been observed in patients convalescing from pneumococcal pneumonia is due to a local union of polysaccharide and antibody in the skin as evidenced by the following facts:

(a) Type-specific pneumococcal antibody is invariably present in the blood of patients convalescing from pneumonia who react positively to the intradermal injection of capsular polysaccharide. A reaction occurs only when the antibody and polysaccharide are of the same type.

(b) By injecting locally at the same site antiserum and capsular polysaccharide of homologous type an immediate wheal and erythema dermal reaction, simulating exactly the Francis skin reaction, has been produced in normal individuals who do not react to the polysaccharide alone.

(c) Positive skin reactions to pneumococcal capsular polysaccharide have been passively transferred to negative reactors by previously sensitizing the skin locally with intradermal injections of blood serum obtained from convalescent patients adequately treated with antipneumococcal serum. Evidence is presented that the factor transferred in the donor's blood serum is the typespecific pneumococcal antibody. 
2. The skin reaction to capsular polysaccharide depends not upon the mere presence of homologous type-specific antibody in the blood but upon the titer of antibody present. In support of this view it has been shown:

(a) that relatively large amounts of antibody must be injected with homologous polysaccharide to produce the characteristic dermal reaction in normal individuals who do not react to the polysaccharide alone, and

(b) that patients with pneumonia, who are being treated with antipneumococcal serum, do not react to polysaccharide as soon as antibody appears in the blood, but only after a relatively large amount of antibody has accumulated.

3. The Francis skin reaction is also dependent in part upon the state of reactivity of the skin. It has been demonstrated that positive reactions are not due solely to an increase in cutaneous reactivity occurring at the time of recovery, but that the skin may occasionally lose its ability to react to capsular polysaccharide during the course of severe pneumonia. The loss of cutaneous sensitivity seems to be associated with general toxemia and probably explains the persistently negative reactions observed in patients who die of pneumonia in spite of the presence of appreciable amounts of antibody in the blood.

\section{BIBLIOGRAPHY}

1. Dochez, A. R., and Avery, O. T., The elaboration of specific soluble substance by pneumococcus during growth. J. Exper. Med., 1917, 26, 477.

2. Cole, R., The neutralization of antipneumococcus immune bodies by injected exudates and sera. J. Exper. Med., 1917, 26, 453.

3. Nye, R. N., and Harris, A. H., Viable pneumococci and pneumococcic specific soluble substance in the lungs from cases of lobar pneumonia. Am. J. Pathol., 1937, 13, 749.

4. Sia, R. H. P., Studies on pneumococcus growth inhibition. VI. The specific effect of pneumococcus soluble substance in the growth of pneumococci in normal serum-leucocyte mixtures. J. Exper. Med., 1926, 43, 633.

5. Ward, H. F., Observations on the phagocytosis of the pneumococcus by human whole blood. I. The normal phagocytic titre and the anti-phagocytic effect of the specific soluble substance. J. Exper. Med., 1930, 51, 675.

6. Finland, M., Adequate dosage in the specific serum treatment of pneumococcus Type I pneumonia. Am. J. M. Sc., 1936, 149, 849.
7. Wood, W. B., The control of the dosage of antiserum in the treatment of pneumococcal pneumonia. II. The clinical application of the Francis skin test. J. Clin. Invest., 1940, 19, 105.

8. Francis, T., Jr., The value of the skin test with typespecific capsular polysaccharide in the serum treatment of Type I pneumococcus pneumonia. J. Exper. Med., 1933, 57, 617.

9. Tillet, W. S., and Francis, T., Jr., Cutaneous reactions to the polysaccharides and proteins of pneumococcus in lobar pneumonia. J. Exper. Med., 1929, 50, 687.

10. Francis, T., Jr., and Tillet, W. S., Cutaneous reactions in pneumonia; the development of antibodies following the intradermal injection of type-specific polysaccharide. J. Exper. Med., 1930, 52, 573.

11. Abernethy, T. J., Concentrated antipneumococcus serum in Type I pneumonia; control of dosage by skin tests with type-specific polysaccharide. New York State J. Med., 1936, 36, 627.

12. MacLeod, C. M., Hoagland, C. L., and Beeson, P. B., The use of the skin test with the type specific polysaccharides in the control of serum dosage in pneumococcal pneumonia. J. Clin. Invest., 1938, 17, 739.

13. Finland, M., and Sutliff, N. D., Specific cutaneous reactions and circulating antibodies in the course of lobar pnuemonia. II. Cases treated with antipneumococcic sera. J. Exper. Med., 1931, 54, 653.

14. Bullowa, J. G., and Sharff, J., Quantitative capsule swelling tests in blood serum of pneumonia patients. J. Infect. Dis., 1937, 61, 55.

15. Reimann, H. A., The Pneumonias. W. B. Saunders Co, Philadelphia, 1938.

16. Felton, L. D., Kauffmann, G., and Stahl, H. J., The precipitation of bacterial polysaccharides with calcium phosphate; pneumococcus. J. Bact., 1935, 29, 149.

17. Sabin, A. B., The microscopic agglutination test in pneumonia; its application to rapid typing and control of serum therapy. J. Infect. Dis., 1930, 46, 469.

18. Alston, J. M., and Lowdon, A. S. R., Studies of the skin reactions to the specific soluble substance of the pneumococcus Types I and II. Brit. J. Exp. Path., 1933, 14, 1.

19. Langley, G. J., Mackay, W., and Stent, L., Studies in pneumonia with special reference to agglutinins. Quart. J. Med., 1936, 5, 251.

20. Marshall, E. K., and Long, P. H., The intravenous use of sodium sulfapyridine. J. A. M. A., 1939, $112,1671$.

21. Mitchell, A. G., Wherry, W. B., Eddy, B., and Stevenson, F. E., Studies in immunity. I. Non-specific factors influencing the reaction of the skin to tuberculin. Am. J. Dis. Child., 1928, 36, 720.

22. Finland, M., and Sutliff, N. D., Specific cutaneous reactions and circulating antibodies in the course of lobar pneumonia. I. Cases receiving no serum therapy. J. Exper. Med., 1931, 54, 637. 